\title{
Formulation, antileukemia mechanism, pharmacokinetics, and biodistribution of a novel liposomal emodin
}

This article was published in the following Dove Press journal:

International Journal of Nanomedicine

7 May 2012

Number of times this article has been viewed

\section{Tiechuang Wang' \\ Xiaodong Yin ${ }^{2}$ \\ Yaping Lu' \\ Weiguang Shan' \\ Subin Xiong'}

'College of Pharmaceutical Sciences, Zhejiang University of Technology, Hangzhou, People's Republic of China;

${ }^{2}$ Baxter International Inc, Shanghai,

People's Republic of China
Correspondence: Subin Xiong I8 Chaowang Road, Zhejiang University of Technology, Hangzhou, 310032, People's Republic of China

Tel +86 57I 88320048

Fax +86 57I 88320048

Email xiongsb@zjut.edu.cn
Abstract: Emodin is a multifunctional Chinese traditional medicine with poor water solubility. $\mathrm{D}-\alpha$-tocopheryl polyethylene glycol 1000 succinate (TPGS) is a pegylated vitamin E derivate. In this study, a novel liposomal-emodin-conjugating TPGS was formulated and compared with methoxypolyethyleneglycol 2000-derivatized distearoyl-phosphatidylethanolamine (mPEG2000-DSPE) liposomal emodin. TPGS improved the encapsulation efficiency and stability of emodin egg phosphatidylcholine/cholesterol liposomes. A high encapsulation efficiency of $95.2 \% \pm 3.0 \%$, particle size of $121.1 \pm 44.9 \mathrm{~nm}$, spherical ultrastructure, and sustained in vitro release of TPGS liposomal emodin were observed; these were similar to mPEG2000-DSPE liposomes. Only the zeta potential of $-13.1 \pm 2.7 \mathrm{mV}$ was significantly different to that for mPEG2000-DSPE liposomes. Compared to mPEG2000-DSPE liposomes, TPGS liposomes improved the cytotoxicity of emodin on leukemia cells by regulating the protein levels of myeloid cell leukemia 1 (Mcl-1), B-cell lymphoma-2 (Bcl-2) and Bcl-2-associated X protein, which was further enhanced by transferrin. TPGS liposomes prolonged the circulation time of emodin in the blood, with the area under the concentration-time curve (AUC) 1.7 times larger than for free emodin and 0.91 times larger than for mPEG2000-DSPE liposomes. In addition, TPGS liposomes showed higher AUC for emodin in the lung and kidney than for mPEG2000DSPE liposomes, and both liposomes elevated the amount of emodin in the heart. Overall, TPGS is a pegylated agent that could potentially be used to compose a stable liposomal emodin with enhanced therapeutics.

Keywords: emodin, liposomes, TPGS, mPEG2000-DSPE, leukemia, transferrin

\section{Introduction}

Emodin is an active anthraquinone from the root and rhizome of Chinese herbs such as Rheum palmatum Linnaeus and Polygonum cuspidatum Sieb. et Zucc. (Figure 1). Emodin shows a wide variety of pharmacological activities such as anticancer, ${ }^{1-4}$ antifibrosis, ${ }^{5-7}$ antirestenosis, ${ }^{8,9}$ and antimicrobial activities. ${ }^{10}$ However, emodin is poorly soluble in water, which limits its applications in vivo.

In a previous publication, emodin exhibited a high affinity for phospholipids such as 1,2-dimiristoyl-sn-glycero-3-phosphocholine (DMPC), 1,2-dimyristoyl-sn-glycero3-[phospho-rac-(1-glycerol)], and 1,2-dielaidoyl-sn-glycero-3-phosphoethanolamine, and emodin in such preparations exhibited stronger antibacterial activity than free emodin. ${ }^{10}$ In addition, silk-fibroin-coated DMPC/Tween20 liposomal emodin was much more effective on breast cancer cells than nontargeted liposomal emodin. ${ }^{11,12}$ However, there were no further in vivo studies reported until now. 


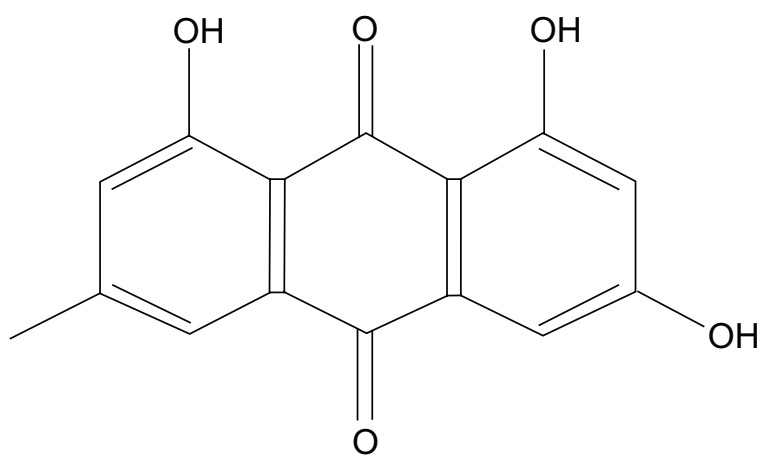

Figure I Chemical structure of emodin.

Liposomal stability and circulation time in the blood are critical for the targeting delivery system, which is strongly influenced by the hydrophilic stealth layer, zeta potential, lipid compositions, particle size and distribution, etc. Methoxypolyethyleneglycol 2000-derivatized distearoylphosphatidylethanolamine (mPEG2000-DSPE) is a widely used stealth modifier in liposomal formulations to provide nanocarriers with a long circulation time and specific stability. Because mPEG2000-DSPE has a polyethylene glycol (PEG) molecular weight of 2000, it not only prevents the contact of liposomes with the targeted cells but also results in side effects such as skin toxicity from its extended circulation time. ${ }^{13}$ Vitamin $\mathrm{E}$ is widely used as an antioxidant agent in liposome formulations or emulsions to avoid phospholipid oxidation. D- $\alpha$-tocopheryl polyethylene glycol 1000 succinate (TPGS) is a water-soluble vitamin E derivate, with a shorter PEG chain than that of mPEG2000-DSPE. Furthermore, TPGS has been demonstrated to achieve a smaller micellar particle size (by reducing the surface tension of lipid membranes) and enhance the micellar stability of poly(ethylene glycol)-phosphatidyl ethanolamine (PEG-PE). ${ }^{14,15}$ Therefore, we hypothesize that TPGS is a potential pegylated alternative to improve the physical stability of liposomes and formulate a liposomal emodin to provide an appropriate circulation time in the blood.

Transferrin receptor (TfR) is a dimeric transmembrane glycoprotein $(180 \mathrm{kDa})$ frequently upregulated in a majority of tumor cells, such as K562 and MV4-11 leukemia cells. ${ }^{16,17}$ Transferrin (Tf), the ligand for TfR, is an $80 \mathrm{kDa}$ irontransporting glycoprotein that can be taken up by cells via TfR-mediated endocytosis. ${ }^{18}$ Tf-conjugated polymers or liposomes have been studied previously for delivering both oligonucleotides and chemotherapeutic agents to achieve selective targeting of tumor cells. ${ }^{19}$

Based on the above, a novel liposomal emodin formulation containing TPGS has been developed in this study.
Encapsulation efficiency (EE), particle size, zeta potential, morphology, in vitro release, pharmacokinetics and biodistributions, in vitro cytotoxicity, and mechanisms of TPGS liposomal emodin with or without $\mathrm{Tf}$ on leukemia cells have been thoroughly compared with mPEG2000-DSPE liposomal emodin.

\section{Methods and materials Materials}

Emodin (99\% purity) was purchased from Shanxi Sciphar Biotechnology Co, Ltd (Xi'an, China). Egg phosphatidylcholine (EPC), hydrogenated soy phosphatidylcholine (HSPC), cholesterol (Chol), distearoylphosphatidylethanolamineN-maleimide polyethylene glycol 3350 (MAL-PEG3350DSPE), and mPEG2000-DSPE were purchased from Avanti Polar Lipids Inc (Alabaster, AL). Human holotransferrin, 2-iminothiolane (Traut's reagent), and 3-(4,5-dimethyl-2thiazolyl)-2,5-diphenyltetrazolium bromide (MTT) were purchased from Sigma Chemical Co (St Louis, MO). TPGS was provided by Eastman Chemical Company (Kingsport, TN). The LiposoFast-Basic ${ }^{\text {TM }}$ Extruder was purchased from Avestin (Ottawa, ON) and the polycarbonate membrane from Whatman (Maidstone, UK).

\section{Liposome preparation}

Emodin liposomes were prepared by thin-film hydration, polycarbonate membrane extrusion. The formulation compositions of transferrin-targeted emodin liposomes and nontargeted emodin liposomes are shown in Table 1. Lipids and emodin were dissolved in a mixture of chloroform $\left(\mathrm{CHCl}_{3}\right)$ : methonal $(\mathrm{V} / \mathrm{V}, 9 / 1)$. The solvents were removed by reduced-pressure evaporation at $40^{\circ} \mathrm{C}$. The formed thin film was hydrated with saline. Extrusion through various sized pore polycarbonate membranes was carried out five times to generate small unilamellar vesicles (SUV).

A postinsertion method was adopted to incorporate the Tf ligand onto the emodin liposomes. Holo-Tf (diferric Tf) was reacted with $5 \times$ Traut's reagent to yield holo-TfSH. Free sulfhydryl content in holo-Tf-SH was measured by Ellman's reagent. The holo-Tf-SH was then reacted to micelles of MAL-PEG3350-DSPE at a molar ratio of 1:10 and then incubated with liposomal emodin for 1 hour at $37^{\circ} \mathrm{C}$. Targeted liposomes with transferrin polyethylene glycol 3350-derivatized distearoyl-phosphatidylethanolamine (Tf-PEG3350-DSPE) to lipids at a molar ratio of 1:200 were prepared. Nontargeted liposomes for studies on cells were prepared by coupling bovine serum albumin instead of Tf to the liposomes, utilizing the same method. 
Table I Encapsulation efficiency and particle size of emodin liposomes based on various formulation compositions and manufacturing processes

\begin{tabular}{llllc}
\hline No & Formulation (molar ratio) & Process & EE (\%) & Particle size (nm) \\
\hline I & EPC/Chol/TPGS (95/0/5) & Ultrasound & $78.2 \pm 2.0$ & $37.5 \pm 22.1$ \\
2 & EPC/Chol/TPGS (75/20/5) & Ultrasound & $82.7 \pm 1.1$ & $40.4 \pm 23.0$ \\
3 & EPC/Chol/TPGS (55/40/5) & Ultrasound & $85.8 \pm 1.3$ & $49.4 \pm 25.6$ \\
4 & EPC/Chol/TPGS (40/55/5) & Ultrasound & $84.4 \pm 1.4$ & $61.0 \pm 41.8$ \\
5 & EPC/Chol/TPGS (50/40//0) & Ultrasound & $84.5 \pm 2.1$ & $44.6 \pm 23.4$ \\
6 & EPC/Chol/TPGS (46/30/23) & Ultrasound & $84.6 \pm 1.8$ & $33.1 \pm 21.5$ \\
7 & EPC/Chol/mPEG2000-DSPE (55/40/5) & Ultrasound & $86.8 \pm 2.3$ & $48.2 \pm 24.5$ \\
8 & EPC/Chol/TPGS (55/40/5) & Extrusion $(50 \mathrm{~nm})$ & $92.8 \pm 0.7$ & $48.5 \pm 24.3$ \\
9 & EPC/Chol/TPGS (55/40/5) & Extrusion $(100 \mathrm{~nm})$ & $95.6 \pm 1.0$ & $91.8 \pm 42.4$ \\
10 & EPC/Chol/TPGS (55/40/5) & Extrusion $(200 \mathrm{~nm})$ & $96.5 \pm 0.9$ & $125.8 \pm 55.1$ \\
II & EPC/Chol/TPGS/Tf-PEG3350-DSPE (55/40/4.5/0.5) & Extrusion $(50 \mathrm{~nm})$ & $93.5 \pm 0.9$ & $49.0 \pm 25.1$ \\
I2 & EPC/Chol/TPGS/Tf-PEG3350-DSPE (55/40/4.5/0.5) & Extrusion $(100 \mathrm{~nm})$ & $95.4 \pm 0.9$ & $94.6 \pm 41.8$ \\
13 & EPC/Chol/TPGS/Tf-PEG3350-DSPE (55/40/4.5/0.5) & Extrusion $(200 \mathrm{~nm})$ & $96.2 \pm 0.6$ & $120.1 \pm 55.6$ \\
\hline
\end{tabular}

Notes: Numbers I-10 refer to nontargeted emodin liposomes. II-13 refer to transferrin-targeted emodin liposomes.

Abbreviations: EE, encapsulation efficiency; EPC, egg phosphatidylcholine; Chol, cholesterol; TPGS, D- $\alpha$-tocopheryl polyethylene glycol I000 succinate; nm, nanometer; mPEG2000-DSPE, methoxypolyethyleneglycol 2000-derivatized distearoyl-phosphatidylethanolamine; Tf-PEG3350-DSPE, transferrin polyethyleneglycol 3350-derivatized distearoyl-phosphatidylethanolamine.

\section{Characteristics of liposomes}

Free emodin and liposomal emodin were separated by size exclusion chromatography on a Sepharose CL-4B column (Sigma-Aldrich, St Louis, MO). Liposomal emodin and the nonseparation emodin liposomes were lysed by $1.0 \%$ Triton X-100 and emodin was determined by high-performance liquid chromatography (HPLC), respectively. The EE was calculated according to the formula:

$$
E E=\frac{W_{\text {liposomal-emodin }}}{W_{\text {nonseparation-emodin-liposomes }}} \times 100 \% \text {. }
$$

The mean diameter and distribution of liposomes were determined by dynamic light scattering using a NICOMP Model 370 Submicron Particle Sizer (Particle Sizing Systems, Santa Barbara, CA).

The zeta potential of liposomes was measured by Zeta PALS (Zeta Potential Analyzer, Brookhaven Instruments Corporation, NY).

The ultrastructure of the emodin liposomes was investigated by transmission electron micrography (JEM-1400; JEOL, Tokyo Japan) after negative staining with sodium phosphotungstate solution $(2 \% \mathrm{w} / \mathrm{v})$.

\section{In vitro release}

Comparisons of emodin released in vitro from liposomes conjugating TPGS or mPEG2000-DSPE were conducted by dialysis. $0.2 \mathrm{~mL}$ of liposomal emodin with an equal volume of media was placed in a dialysis tube (molecular weight cut-off 12,000-14,000; Spectrum Laboratories, Inc, Rancho Dominguez, CA) and then suspended in $50 \mathrm{~mL}$ of citrate buffer (pH 5.0) or phosphate-buffered saline (PBS; pH 7.4) at $37^{\circ} \mathrm{C}$. To investigate the influence of serum albumin on the in vitro release, $0.2 \mathrm{~mL}$ of liposomal emodin was mixed with an equal volume of human plasma, placed in the dialysis tube, and then suspended in $50 \mathrm{~mL}$ of PBS (pH 7.4). At predetermined time intervals, aliquots were withdrawn and emodin was assayed by HPLC.

\section{Cell culture}

L1210 and K562 cells were cultured in an RPMI 1640 media (Life Technologies, Inc, Bethesda, MD), MV4-11 cells were cultured in DMEM media (Life Technologies, Inc), supplemented with $50 \mu \mathrm{g} / \mathrm{mL}$ penicillin, $50 \mu \mathrm{g} / \mathrm{mL}$ streptomycin, and $10 \%$ fetal bovine serum. Cells were maintained in a humidified atmosphere containing $5 \% \mathrm{CO}_{2}$ at $37^{\circ} \mathrm{C}$.

\section{In vitro cytotoxicity}

Cytotoxicity of liposomal emodin formulations on leukemia cell lines was determined using MTT. Briefly, cells were harvested during the logarithmic growth phase and seeded in 96-well plates at a final density of $2-4 \times 10^{3}$ per well. After 24 hours of incubation, the culture medium was replaced by $200 \mu \mathrm{L}$ of fresh media containing serial dilutions of emodin formulations. Following 72 hours of treatment at $37^{\circ} \mathrm{C}$ in the incubator, $20 \mu \mathrm{L}$ of MTT solution $(5 \mathrm{mg} / \mathrm{mL})$ was added to each well, and the plates were incubated for another 4 hours. Then the medium was removed after centrifugation 
at $2000 \mathrm{rpm}$ for 10 minutes. $200 \mu \mathrm{L}$ of dimethyl sulfoxide (DMSO) was added to each well to dissolve the blue formazan crystal converting from the MTT. Cell viability was assessed by absorbance at $570 \mathrm{~nm}$ on a microplate reader (Bio-Rad Laboratories, Richmond, CA), and the half maximal inhibitory concentration $\left(\mathrm{IC}_{50}\right)$ was used to measure the effectiveness of various formulations.

\section{Western blot analysis}

Western blotting was used to determine the protein level of B-cell lymphoma-2 (Bcl-2), myeloid cell leukemia 1 (Mcl-1), and Bcl-2-associated X protein (Bax) in the K562 and MV 4-11 cells after treatment using emodin formulations for 72 hours. Briefly, cells were seeded in 12-well plates at a final density of $2-4 \times 10^{3}$ per well. After 24 hours of incubation, the culture medium was replaced by $1000 \mu \mathrm{L}$ of fresh media containing serial dilutions of emodin formulations. After 72 hours of treatment in the incubator, the cells were washed three times with cold PBS, harvested and lysed using a $1 \times$ cell lysis buffer containing a protease inhibitor cocktail (CalBiochem, San Diego, CA). Then, the supernatants were collected after centrifugation at $12,000 \mathrm{~g}$ for 15 minutes at $4^{\circ} \mathrm{C}$. The protein concentrations in the supernatants were determined using bicinchoninic acid. Approximately $20 \mu \mathrm{g}$ of cellular protein was loaded and separated using $12.5 \%$ sodium dodecyl sulfate polyacrylamide gel electrophoresis. After that, the proteins were transferred electrophoretically onto nitrocellulose membranes $(0.2 \mathrm{~mm}$; Schleicher and Schuell, Keene, NH). The membranes were then blocked with 5\% nonfat dried milk in Tris-buffered saline and subsequently probed with a primary antibody, such as polyclonal rabbit anti-human Bcl-2, polyclonal rabbit anti-human Mcl-1, polyclonal rabbit anti-human Bax, and polyclonal goat anti-human $\beta$-actin (Santa Cruz Biotech, Santa Cruz, CA) in Tris-buffered saline containing 3\% nonfat dried milk, respectively. Antibody-antigen complexes were detected using goat anti-rabbit immunoglobulin G-horseradish peroxidase-conjugated antibodies and an enhanced chemiluminescence detection kit (Amersham Pharmacia Biotech, San Francisco, CA). Bcl-2, Mcl-1, and Bax protein expression levels were quantified by using ImageJ software (National Institutes of Health, Bethesda, MD) and were normalized to the $\beta$-actin levels.

\section{In vivo animal study}

Animals

Imprinting Control Region mice weighing 20-22 g were purchased from Shanghai Slac Laboratory Animal Co, Ltd
(Shanghai, People's Republic of China). All mice were fed and maintained under constant conditions at temperature of $20^{\circ} \mathrm{C}-25^{\circ} \mathrm{C}$, humidity $55 \% \pm 5 \%$, with cycles of 12 hours of light and 12 hours of dark. Water and food were accessible to mice ad libitum. All animal experiments were performed according to international ethical standards, and the protocol was approved by the Institutional Animal Ethics Committee of Zhejiang University of Technology (Zhejiang, People's Republic of China).

\section{Pharmacokinetics and biodistribution}

Imprinting control region mice (age 6-8 weeks, half male and half female) were randomly divided into three groups of 30 each for TPGS liposomal emodin, mPEG2000-DSPE liposomal emodin, and free emodin solution. A single dose of emodin at $5 \mathrm{mg} / \mathrm{kg}$ was intravenously injected into each mouse. At 5, 15, 30, 60, 120, and 240 minutes after the drug administration, animals (five per time for each group) were sacrificed. Blood was taken from the orbital sinus and collected in tubes with heparin, and plasma was obtained by centrifugation at $3500 \mathrm{rpm}$ for 5 minutes. Tissues, such as heart, lung, liver, spleen, and kidney, were extracted, washed with cold saline, blotted with filter paper, and weighed. Both plasma and tissues were stored at $-20^{\circ} \mathrm{C}$ until assay.

\section{Biosample preparation}

Weighed tissue samples were homogenized in saline to get a tissue concentration of $0.25 \mathrm{~g} / \mathrm{mL}$. First, $200 \mu \mathrm{L}$ plasma or tissue homogenates were put in $1.5 \mathrm{~mL}$ Eppendorf tubes. Then, $40 \mu \mathrm{L} \mathrm{NaOH}(2.5 \mathrm{~mol} / \mathrm{L})$ and $1 \mathrm{~mL}$ ethyl acetate were added and vigorously mixed for 2 minutes. After that, $60 \mu \mathrm{L}$ of $\mathrm{HCl}(3 \mathrm{~mol} / \mathrm{L})$ was added and vigorously mixed for 1.5 minutes to neutralize the $\mathrm{NaOH}$. The mixture was centrifuged at 10,000 rpm for 6 minutes. The supernatant of $0.8 \mathrm{~mL}$ was transferred to a fresh $1.5 \mathrm{~mL}$ Eppendorf tube and dried by an air stream at $70^{\circ} \mathrm{C}$. The residues were reconstituted in $100 \mu \mathrm{L}$ of methanol and centrifuged at 10,000 rpm for 10 minutes before determination. A sample $(15 \mu \mathrm{L})$ was injected into HPLC.

\section{Determination of emodin}

Emodin levels were determined by a HPLC-ultraviolet method (LC-10 ADT pump, SPD-10 A UV-VIS detector; Shimadazu, Kyoto, Japan) utilizing a $4.6 \times 250 \mathrm{~mm}$ ODS column ( $5 \mu \mathrm{m}$; Elite, Dalian, People's Republic of China), preceded by a $5 \mathrm{~mm}$ guard column packed with ODS at column temperature of $30^{\circ} \mathrm{C}$ and wavelength of $290 \mathrm{~nm}$. The mobile phase was a mixture of $0.2 \%$ acetic acid 
solution (pH 3.0) and methanol (20:80) at a flow rate of $0.8 \mathrm{~mL} /$ minute. The chromatographic data were analyzed using N2000 software (Zhejiang University, Zhejiang, People's Republic of China).

\section{Statistical analysis}

Data were reported as the mean \pm standard deviation. Statistical significance was measured by Student's $t$-test and defined by $P<0.05$.

\section{Results and discussion Formulation of liposomes}

Emodin is a poorly water-soluble anthraquinone drug. Thinfilm-hydration was used to prepare emodin liposomes. In this study, the influences of formulation composition and manufacturing process on the emodin liposomes have been investigated.

$\mathrm{EE}$ and particle size of emodin liposomes based on various lipids, pegylated agents, targeting anchor, ultrasound, and extrusion are summarized in Table 1. When the molar ratio of pegylated agent was zero, emodin was inclined to leak out from liposomes and recrystallize after overnight storage at $4^{\circ} \mathrm{C}$ (data not shown in Table 1). Interestingly, the particle size of emodin EPC/Chol/TPGS liposomes, prepared by ultrasound at $7 \mathrm{~W}$ for 30 seconds, decreased from $49.4 \pm 25.6 \mathrm{~nm}$ to $33.1 \pm 21.5 \mathrm{~nm}$ with the molar ratio of TPGS increasing from $5 \%$ to $23 \%$, while the EE was not significantly influenced $(P>0.05)$. TPGS is a hydrophilic derivative of vitamin E-conjugated PEG 1000, with a hydrophilic-lipophilic balance of 13 and a critical micelle concentration of $26 \mu \mathrm{mol} / \mathrm{L}$. Concentrations of TPGS in the EPC/ Chol liposomes were above its critical micelle concentration. From these results, a higher ratio of TPGS resulted in smaller liposome particle size without significantly changing the EE; we can deduce that emodin was encapsulated in phospholipid liposomes, while not in TPGS micelles. On the other hand, TPGS may work as a pegylated agent by inserting a hydrophobic chain of vitamin $E$ into the phospholipid bilayers and spreading out a PEG 1000 chain in the water phase to obtain the stable emodin liposomes.

The influences of EPC/Chol ratio on the EE and particle size at $5 \%(\mathrm{~mol})$ TPGS were also investigated. With the molar ratio of cholesterol increasing from $0 \%$ to $55 \%$, the particle size increased from $37.5 \pm 22.1 \mathrm{~nm}$ to $61.0 \pm 41.8 \mathrm{~nm}$, while the highest $\mathrm{EE}(85.8 \% \pm 1.3 \%)$ was obtained in the $\mathrm{EPC} / \mathrm{Chol}$ $(55 / 40)(P<0.03)$. These suggest that suitable amount of cholesterol could also stabilize the phospholipid bilayers and elevate the entrapment of emodin in the TPGS liposomes.
Ultrasound reduces the liposome particle size by vigorously ultrasonic cavitation, which may result in the partial leakage of the drug from the liposomes. In this work, extrusion through polycarbonate membrane using nitrogen was also studied. In comparison with the ultrasound method (EE $85.8 \% \pm 1.3 \%$ and particle size $49.4 \pm 25.6 \mathrm{~nm}$ ), significantly higher EE $(92.8 \% \pm 0.7 \%)$ and similar particle size $(48.5 \pm 24.3 \mathrm{~nm}$ of EPC/Chol/TPGS 55/40/5) were achieved by extrusion five times through pore size $50 \mathrm{~nm}$ polycarbonate membrane $(P<0.002)$. In addition, with a pore size increase from $50 \mathrm{~nm}$ to $200 \mathrm{~nm}$, particle sizes increased from $48.5 \pm 24.3 \mathrm{~nm}$ to $125.8 \pm 55.1 \mathrm{~nm}$ and the emodin entrapments were also improved from $92.8 \% \pm 0.7 \%$ to $97.5 \% \pm 0.9 \%(P<0.02)$. These data indicate that extrusion could avoid the ultrasonic leakage of liposomes and result in much higher encapsulation of emodin.

Further comparisons of TPGS and mPEG2000-DSPE on the emodin liposomes were carried out by either ultrasound or extrusion. At the same lipid molar ratio of 55/40/5, both EPC/Chol/TPGS and EPC/Chol/mPEG2000-DSPE liposomes showed a similar EE and a similar particle size using both ultrasound (Table 1) and extrusion (Table 2). These data show that TPGS may be a potentially alternative pegylated agent to $\mathrm{mPEG} 2000-\mathrm{DSPE}$.

Tf-tailored targeted emodin liposomes were composed by postinserting Tf-PEG3350-DSPE micelles into EPC/Chol/ TPGS emodin liposomes. Results indicated that insertion of Tf-PEG3350-DSPE did not significantly affect the EE and particle size $(P>0.19)$ (Table 1).

It has been reported that emodin has a high affinity for phospholipids such as DMPC, 1,2-dimyristoyl-sn-glycero-3[phospho-rac-(1-glycerol)], and 1,2-dielaidoyl-sn-glycero-3phosphoethanolamine. ${ }^{10}$ This study also investigated HSPC as a phospholipid to compose emodin liposomes. It is surprising that similar entrapment of HSPC liposomes was obtained compared to EPC liposomes, while most of the emodin leaked out from the HSPC bilayers after several hours of storage. A possible reason is that emodin is an anthraquinone drug

Table 2 Properties of emodin liposomes from extrusion

\begin{tabular}{llll}
\hline Formulations & EE $(\%)$ & $\begin{array}{l}\text { Particle } \\
\text { size }(\mathbf{n m})\end{array}$ & $\begin{array}{l}\text { Zeta potential } \\
(\mathbf{m V})\end{array}$ \\
\hline $\begin{array}{l}\text { TPGS liposomal } \\
\text { emodin }\end{array}$ & $95.2 \pm 3.0$ & $121.1 \pm 49.2$ & $-13.1 \pm 2.7$ \\
$\begin{array}{l}\text { mPEG2000-DSPE } \\
\text { liposomal emodin }\end{array}$ & $94.2 \pm 1.8$ & $121.7 \pm 44.9$ & $-41.7 \pm 0.9$ \\
\hline
\end{tabular}

Abbreviations: $\mathrm{EE}$, encapsulation efficiency; $\mathrm{nm}$, nanometer; $\mathrm{mV}$, millivolt; EPC, egg phosphatidylcholine; TPGS, D- $\alpha$-tocopheryl polyethylene glycol 1000 succinate; mPEG2000-DSPE, methoxypolyethyleneglycol 2000-derivatized distearoylphosphatidylethanolamine. 
with poor water solubility which was incorporated in the phospholipid bilayers to form liposomes. EPC is a nonsaturated phospholipid with a lower crystallization temperature than HSPC. Thus, emodin could move freely in the EPC bilayers, and the molecular interactions of emodin with EPC could reform quickly when the biomembranes crystallized. On the other hand, HSPC liposomes have solid structures, which forced emodin out of the HSPC bilayers during the microphase transformation. The above data suggest that EPC composed of TPGS or mPEG2000-DSPE is a potential carrier for emodin.

\section{Characteristics of liposomes}

The EPC/Chol/TPGS and EPC/Chol/mPEG2000-DSPE liposomes (55/40/5 molar ratio) for loading emodin were prepared by thin-film-hydration-extrusion at an emodin-to-lipids weight ratio of $1 / 20$ and an emodin concentration of $0.5 \mathrm{mg} / \mathrm{mL}$. The properties of both liposomes have been compared. Data indicated that there were no significant differences for $\mathrm{EE}$ and particle size $(P>0.32)$ (Table 2$)$. Due to the negative charge from $\mathrm{mPEG} 2000-\mathrm{DSPE}$, the absolute zeta potential of the mPEG2000-DSPE liposomes $(41.7 \pm 0.9 \mathrm{mV})$ was higher than that of the TPGS liposomes $(13.1 \pm 2.7 \mathrm{mV})$.

The unilamellar vesicles with bright circles surrounding dark chambers can be seen in the liposomes on the upper layer, as shown in Figure 2. Due to the low crystallization temperature of EPC, some liposomes exhibited flowability, contacted each other and distorted. No significant differences between TPGS liposomal emodin and mPEG2000-DSPE liposomal emodin can be observed. Interestingly, the EE, particle size, and micromorphology of both liposomes remained similar even after storage for 2 years at $4^{\circ} \mathrm{C}$, which further indicates that TPGS could form a steric layer around the EPC liposomes to stabilize the liposomal emodin.

\section{In vitro release}

To mimic the in vivo properties of liposomes, the in vitro release of TPGS and mPEG2000-DSPE liposomal emodin in PBS ( $\mathrm{pH}$ 7.4), plasma, and citrate buffer ( $\mathrm{pH}$ 5.0) by dialysis were compared. The release profiles of TPGS liposomal emodin were similar to mPEG2000-DSPE liposomal emodin in three media (Figure 3). In the PBS ( $\mathrm{pH} 7.4$ ), both emodin liposomes released about $22 \%$ of the emodin in the first 24 hours, but from then until 72 hours, only $6 \%$ of the emodin was gradually released (Figure $3 \mathrm{~A}$ ). Of note, plasma mixed with emodin liposomes in the dialysis bag inhibited emodin releasing into the PBS ( $\mathrm{pH} 7.4$ ) and resulted in only $16 \%$ of the emodin being released over 72 hours, as shown in
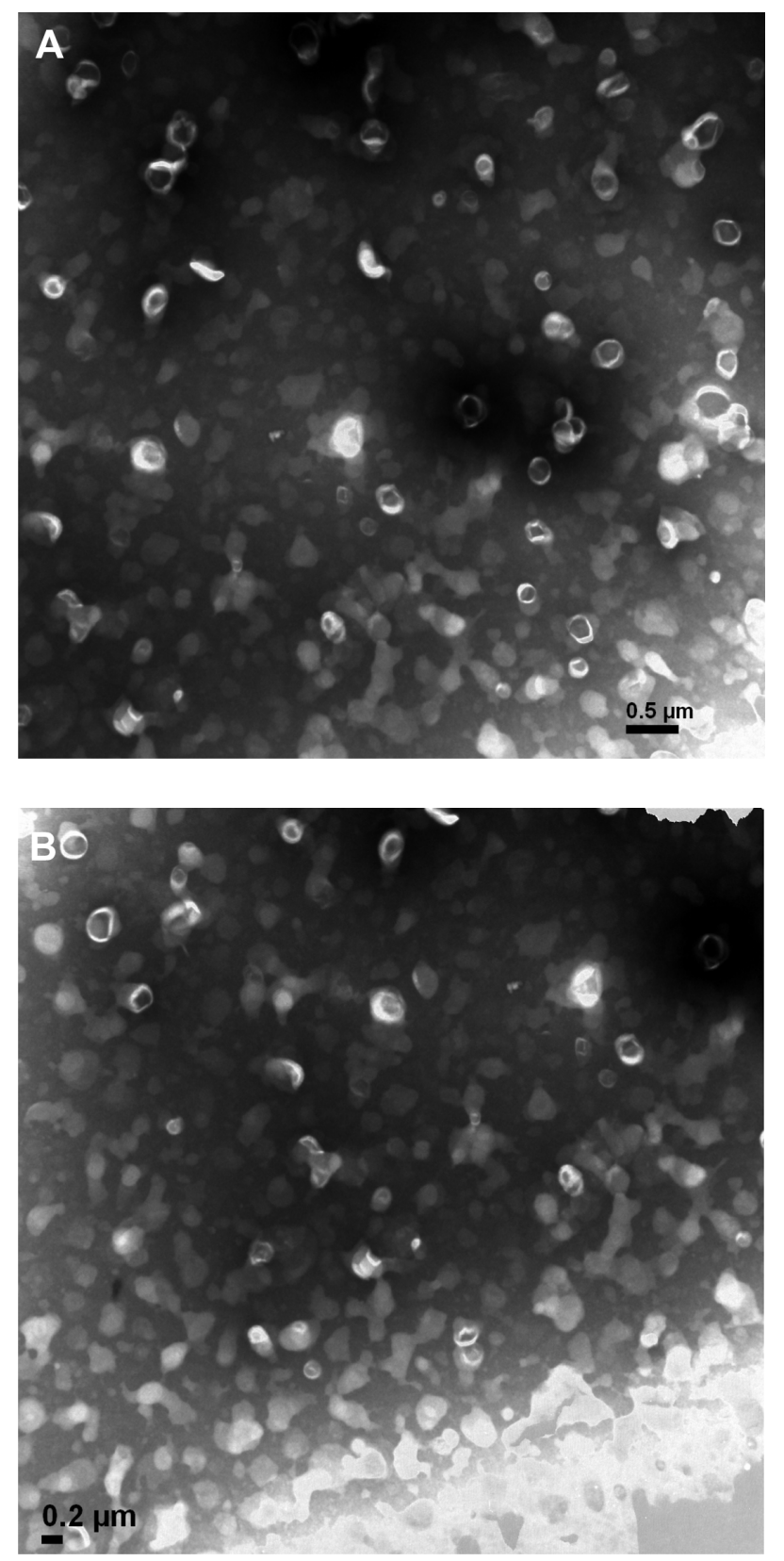

Figure 2 Transmission electron microscope pictures of emodin liposomes by negative staining with sodium phosphotungstate solution $(\times 20,000)$. (A) TPGS liposomal emodin; (B) mPEG2000-DSPE liposomal emodin.

Abbreviations: TPGS, D- $\alpha$-tocopheryl polyethylene glycol 1000 succinate; mPEG2000-DSPE, methoxypolyethyleneglycol 2000-derivatized distearoylphosphatidylethanolamine.

Figure 3B. It has been reported that emodin has a high protein binding efficiency of $99.6 \% .{ }^{20}$ When the mixtures of emodin liposomes (EE 78.8\%) and plasma (1/4, V/V) were incubated at $37^{\circ} \mathrm{C}$ for 2 hours, the EE was raised about $5 \%$ for both TPGS and mPEG2000-DSPE liposomes. Thus, we deduce that the released emodin may conjugate with the plasma protein and cannot pass through the dialysis tube. To mimic the release ability of emodin liposomes from endosomes 
A

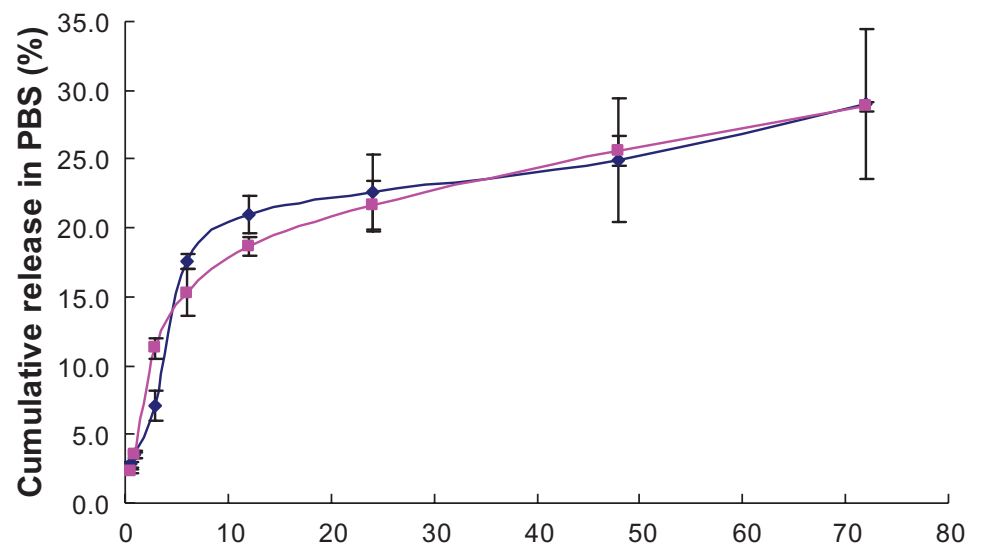

B

Time (h)
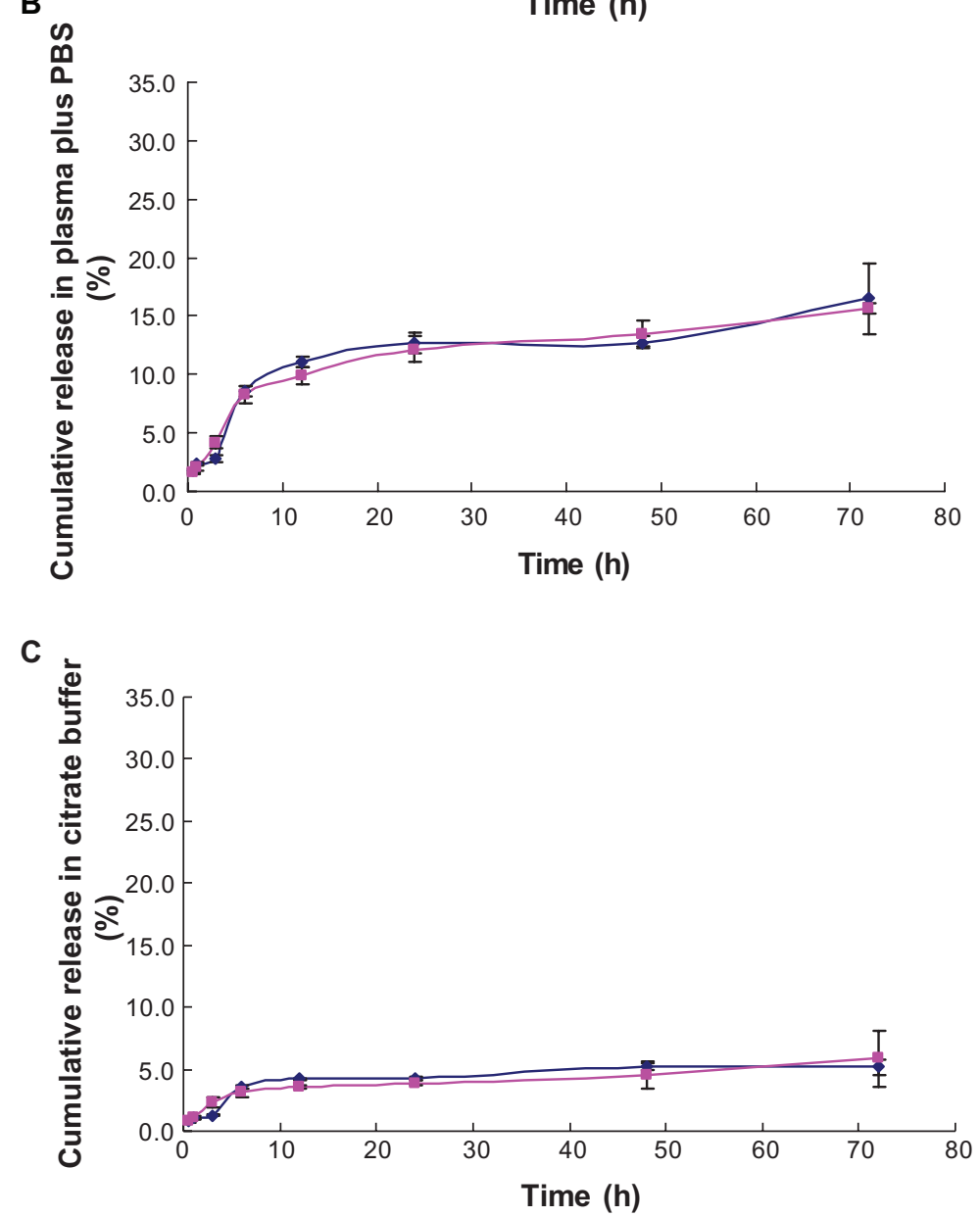

Figure 3 In vitro release profiles of emodin liposomes by dialysis against three media. (A) emodin liposomes against PBS (pH 7.4); (B) emodin liposomes plus equal volume of plasma against PBS ( $\mathrm{pH} 7.4)$; (C) emodin liposomes against citrate buffer ( $\mathrm{pH} 5.0)$.

Notes: ( $\Delta$ : mPEG2000-DSPE liposomal emodin; $\$$ : TPGS liposomal emodin); error bars refer to standard deviations, $\mathrm{n}=3$.

Abbreviations: PBS, phosphate-buffered saline; TPGS, D- $\alpha$-tocopheryl polyethylene glycol 1000 succinate; mPEG2000-DSPE, methoxypolyethyleneglycol 2000-derivatized distearoyl-phosphatidylethanolamine.

with $\mathrm{pH} 5.0-6.5$, in vitro release in the citrate buffer $(\mathrm{pH} 5.0)$ was carried out. Figure $3 \mathrm{C}$ showed that the smallest amount of emodin was released from the liposomes (about 5\%). A possible reason is that there are three phenolic hydroxyls in emodin's molecular structure, which give it lower solubility in an acidic buffer. Although the in vitro release methods demonstrate this deficiency to some degree in this work, the above results suggest that TPGS does not affect the in vitro release of emodin from liposomes in comparison with mPEG2000-DSPE. 


\section{Cell viability}

Emodin exerts specifically antiproliferative effects to many cancer cells such as leukemia, ${ }^{1,21}$ breast cancer, ${ }^{12}$ lung cancer, ${ }^{2,22}$ and human hepatocellular carcinoma ${ }^{4}$ in vitro. To investigate whether TPGS liposomes enhance the cytotoxicity of emodin, the cell viability of leukemia cells was tested.

Cytotoxicity of TPGS liposomal emodin, mPEG2000DSPE liposomal emodin, and free emodin on L1210 leukemia cells showed that when L1210 cells are exposed to low concentrations of emodin, there was no difference to cell viability among various formulations. At concentrations higher than $10 \mu \mathrm{mol} / \mathrm{L}$, TPGS liposomal emodin presented a stronger inhibition to L1210 cells than mPEG2000-DSPE liposomal emodin and free emodin. The $\mathrm{IC}_{50}$ indicated that TPGStailored liposomes enhanced the cytotoxicity of emodin, with an $\mathrm{IC}_{50}$ value only 0.21 times that of free emodin, while mPEG2000-DSPE liposomes diminished the cytotoxicity of emodin to a certain degree (Table 3 ). In addition, empty TPGS liposomes showed a similar $\mathrm{IC}_{50}(72 \mu \mathrm{mol} / \mathrm{L})$ to free emodin $(63 \mu \mathrm{mol} / \mathrm{L})$. However, it is of note that at the $\mathrm{IC}_{50}$ of TPGS liposomal emodin $(13.2 \mu \mathrm{mol} / \mathrm{L})$, the concentration of TPGS is $17.2 \mu \mathrm{mol} / \mathrm{L}$, while the cell viability of empty TPGS liposomes at TPGS $17.2 \mu \mathrm{mol} / \mathrm{L}$ is $85.4 \% \pm 6.2 \%$. Thus, the enhanced cytotoxicity of emodin is not simply the additive result of the free emodin and empty TPGS liposomes.

The transferrin receptor is overexpressed on leukemia cells such as K562 and MV4-11, and it has been evaluated and used in transferrin-mediated targeting delivery to leukemia cells. ${ }^{16,17}$ To further study the antileukemia efficacy of TPGS liposomal emodin, Tf-targeted vesicles were composed by postinserting Tf-PEG3350-DSPE. The cytotoxicity of various emodin formulations on K562 and MV4-11 cells was compared. Data showed that TPGS liposomes also enhanced the cytotoxicity of emodin to K562 and MV 4-11 cells in comparison with free emodin, with $\mathrm{IC}_{50} 31.2 \mu \mathrm{mol} / \mathrm{L}$ and $20.5 \mu \mathrm{mol} / \mathrm{L}$ of free emodin decreasing to $21.8 \mu \mathrm{mol} / \mathrm{L}$ and $11.6 \mu \mathrm{mol} / \mathrm{L}$ of nontargeted TPGS liposomal emodin (100 nm), respectively (Table 4). Mean

Table $3 \quad I_{50}$ of $\mathrm{LI} 210$ cells exposed to various emodin formulations for 72 hours

\begin{tabular}{ll}
\hline Formulations & IC $_{50}(\mu \mathrm{mol} / \mathbf{L})$ \\
\hline TPGS liposomal emodin & 13.2 \\
mPEG2000-DSPE liposomal emodin & 90.5 \\
Free emodin & 64.3 \\
Empty TPGS liposomes & 72.0 \\
\hline
\end{tabular}

Abbreviations: $\mathrm{IC}_{50}$, half maximal inhibitory concentration; $\mu \mathrm{mol}$, micromole; L, liter; TPGS, D- $\alpha$-tocopheryl polyethylene glycol 1000 succinate; mPEG2000-DSPE, methoxypolyethyleneglycol 2000-derivatized distearoyl-phosphatidylethanolamine.
Table $4 I_{50}$ of K562 and MV4-II cells exposed to various emodin formulations for 72 hours

\begin{tabular}{lll}
\hline Formulations & \multicolumn{2}{l}{ IC $_{50}(\mu \mathrm{mol} / \mathbf{L})$} \\
\cline { 2 - 3 } & $\mathbf{K 5 6 2}$ & MV4-I I \\
\hline Tf-targeted TPGS liposomal emodin $(100 \mathrm{~nm})$ & 18.4 & 9.6 \\
Nontargeted TPGS liposomal emodin $(100 \mathrm{~nm})$ & 21.8 & 11.6 \\
Nontargeted TPGS liposomal emodin $(50 \mathrm{~nm})$ & 21.3 & 11.2 \\
Free emodin & 31.2 & 20.5 \\
\hline
\end{tabular}

Abbreviations: $\mathrm{IC}_{50}$, half maximal inhibitory concentration; $\mu \mathrm{mol}$, micromole; L, liter; Tf, transferrin; TPGS, D- $\alpha$-tocopheryl polyethylene glycol 1000 succinate; $\mathrm{nm}$, nanometer; mPEG2000-DSPE, methoxypolyethyleneglycol 2000-derivatized distearoyl-phosphatidylethanolamine.

volume particle sizes of $100 \mathrm{~nm}$ and $50 \mathrm{~nm}$ had almost no influence on the $\mathrm{IC}_{50}$ of the nontargeted liposomes. Further, Tf-PEG3350-DSPE improved the cytotoxicity of TPGS liposomal emodin, with $\mathrm{IC}_{50}$ diminishing to $18.4 \mu \mathrm{mol} / \mathrm{L}$ and $9.6 \mu \mathrm{mol} / \mathrm{L}$, respectively.

\section{Mechanisms of emodin for leukemia}

The Bcl-2 family of proteins are the best-characterized regulators of apoptosis. Some members in this family, such as Bcl-2, Bcl-XL, and Mcl-1, suppress apoptosis, while Bax and Bcl-2 homologous antagonist/killer promote apoptosis. Downregulation of Bcl-2 and Mcl-1 and upregulation of Bax can potentially indicate the apoptosis of tumor cells. Mechanisms of emodin cytotoxicity based on the Bcl-2 family have also been investigated. Downregulated Bcl-2 along with unaffected Bax was found in human $\mathrm{H} 460$ non-small-cell lung cancer cell lines. ${ }^{2}$ Upregulation of the Bax/Bcl-2 ratio was reported in human neuroblastoma cell lines SJ-N-KP ${ }^{23}$ and human lung squamous carcinoma cell line $\mathrm{CH} 27 .{ }^{22}$ Emodin decreased Mcl-1, but did not significantly affect the expressions of Bcl-2 and Bax proteins in myeloma cells, such as U266, IM-9, KMS-12-PE, RPMI8226, ${ }^{1}$ and HL-60, ${ }^{24}$ have also been reported.

To clarify whether the expressions of these cell-deathrelated proteins are involved in emodin-induced apoptosis on K562 and MV4-11 leukemia cells, the Western blotting technique was utilized to test the level of proteins, such as Bcl-2, Bax, and Mcl-1.

Western blot images showed that when K562 cells were exposed to free emodin, the proteins were almost unchanged with emodin concentrations from 0 to $80 \mu \mathrm{mol} / \mathrm{L}$ (Figure 4A). However, in the TPGS liposomal emodin and Tf-targeted TPGS liposomal emodin groups, downregulation of Mcl-1 protein and upregulation of Bax protein were clearly observed with the concentrations as shown in Figure 4B and C. Protein amounts were calculated using ImageJ software. In comparison with the control (empty vesicles), Bax protein was upregulated 
A

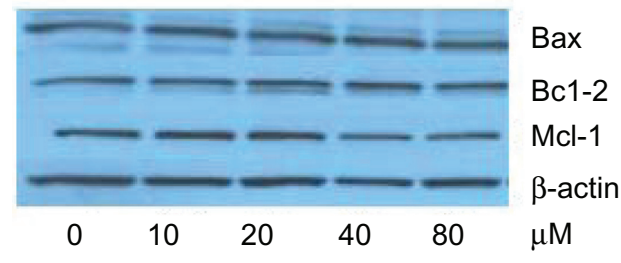

B

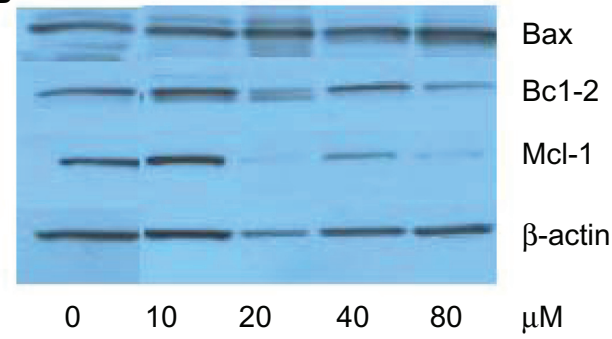

C

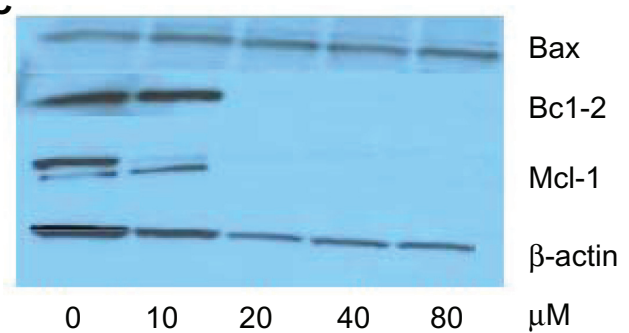

Figure 4 Western blot images of $\mathrm{K} 562$ cells exposed to various emodin formulations for 72 hours. (A) free emodin (0 refers to dimethyl sulfoxide); (B) TPGS liposomal emodin (0 refers to empty TPGS liposomes); (C) Tf-targeted TPGS liposomal emodin (0 refers to empty Tf-targeted TPGS liposomes).

Abbreviations: Bax, Bcl-2-associated X protein; Bcl-2, B-cell lymphoma-2; Mcl-I, myeloid cell leukemia I; TPGS, D- $\alpha$-tocopheryl polyethylene glycol 1000 succinate; Tf, transferrin.

twofold by TPGS liposomes and about 3.5-fold by Tf-targeted TPGS liposomes when the emodin concentration was higher than $20 \mu \mathrm{mol} / \mathrm{L}$. The Bcl-2 protein level of the $\mathrm{K} 562$ cells was 0.7 times that of empty TPGS liposomes after exposure to $80 \mu \mathrm{mol} / \mathrm{L}$ TPGS liposomal emodin for 72 hours. Of particular note, the nearly total downregulation of Bcl-2 was observed by Tf-targeted TPGS liposomal emodin above $20 \mu \mathrm{mol} / \mathrm{L}$. Furthermore, Mcl-1 protein of K562 cells was almost totally downregulated by both Tf-targeted liposomal emodin and nontargeted liposomal emodin above $20 \mu \mathrm{mol} / \mathrm{L}$. While in exposure to $80 \mu \mathrm{mol} / \mathrm{L}$ free emodin, Mcl-1 protein showed only 0.4 times that of the control (DMSO).

In contrast to K562 cells, Bax protein levels in MV4-11 cells were not influenced by emodin formulations (Figure 5). Bcl-2 protein downregulation was obtained when emodin concentration higher than $40 \mu \mathrm{mol} / \mathrm{L}$ in various formulations. It is worthy of note that almost total downregulation of Mcl-1 was also observed in the free emodin of $80 \mu \mathrm{mol} / \mathrm{L}$ (Figure 5A) and in the nontargeted liposomes and Tf-targeted liposomes of more than $40 \mu \mathrm{mol} / \mathrm{L}$ (Figure 5B and C).
A

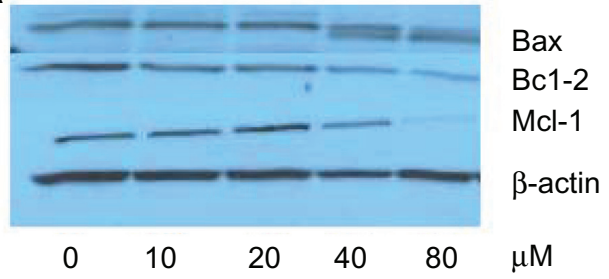

B
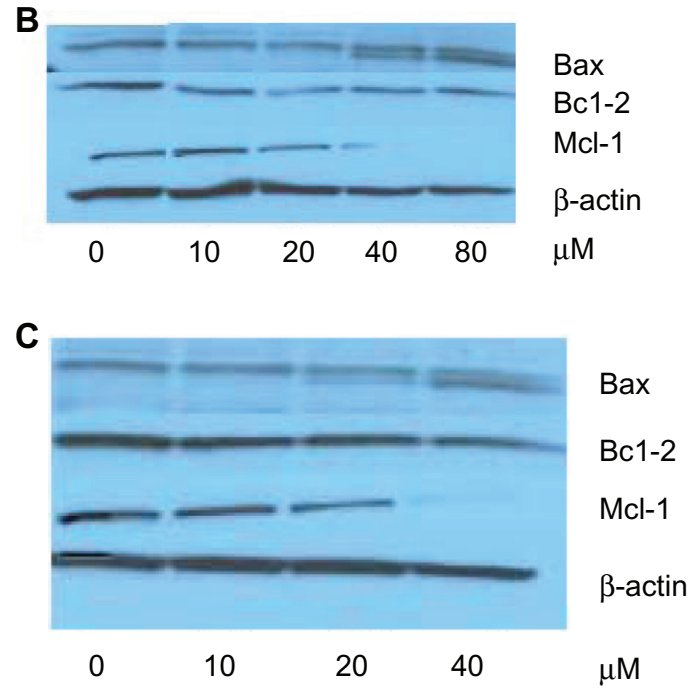

Figure 5 Western blot images of MV4-II cells exposed to various emodin formulations for 72 hours. (A) Free emodin (0 refers to dimethyl sulfoxide); (B) TPGS liposomal emodin (0 refers to empty TPGS liposomes); (C) Tf-targeted TPGS liposomal emodin ( 0 refers to empty Tf-targeted TPGS liposomes). Abbreviations: Bax, Bcl-2-associated X protein; Bcl-2, B-cell lymphoma-2; Mcl-I, myeloid cell leukemia I; TPGS, D- $\alpha$-tocopheryl polyethylene glycol I 000 succinate; Tf, transferrin.

In addition, we have observed that the total amount of proteins decreased with increased concentration of emodin formulations on K562 or MV4-11 cells for 72 hours. Interestingly, the emodin concentrations at half the amount of total proteins assayed using bicinchoninic acid agreed with the corresponding $\mathrm{IC}_{50}$.

The above data suggest that emodin can induce the apoptosis of leukemia cells. TPGS liposomes enhance the cytotoxicity of emodin to K562 and MV4-11 cells by downregulation of Bcl-2 and Mcl-1 protein expressions, which is further improved by Tf-mediated active endocytosis.

\section{Pharmacokinetics and biodistribution}

To investigate the in vivo properties of TPGS liposomal emodin in comparison with mPEG2000-DSPE liposomal emodin and free emodin, pharmacokinetic and biodistribution studies were carried out in mice. Emodin formulations were administered by intravenous injection at a dose of $5 \mathrm{mg} / \mathrm{kg}$.

Data, shown in Figure 6, indicated that when emodin was administered after intravenous bolus injection, the 


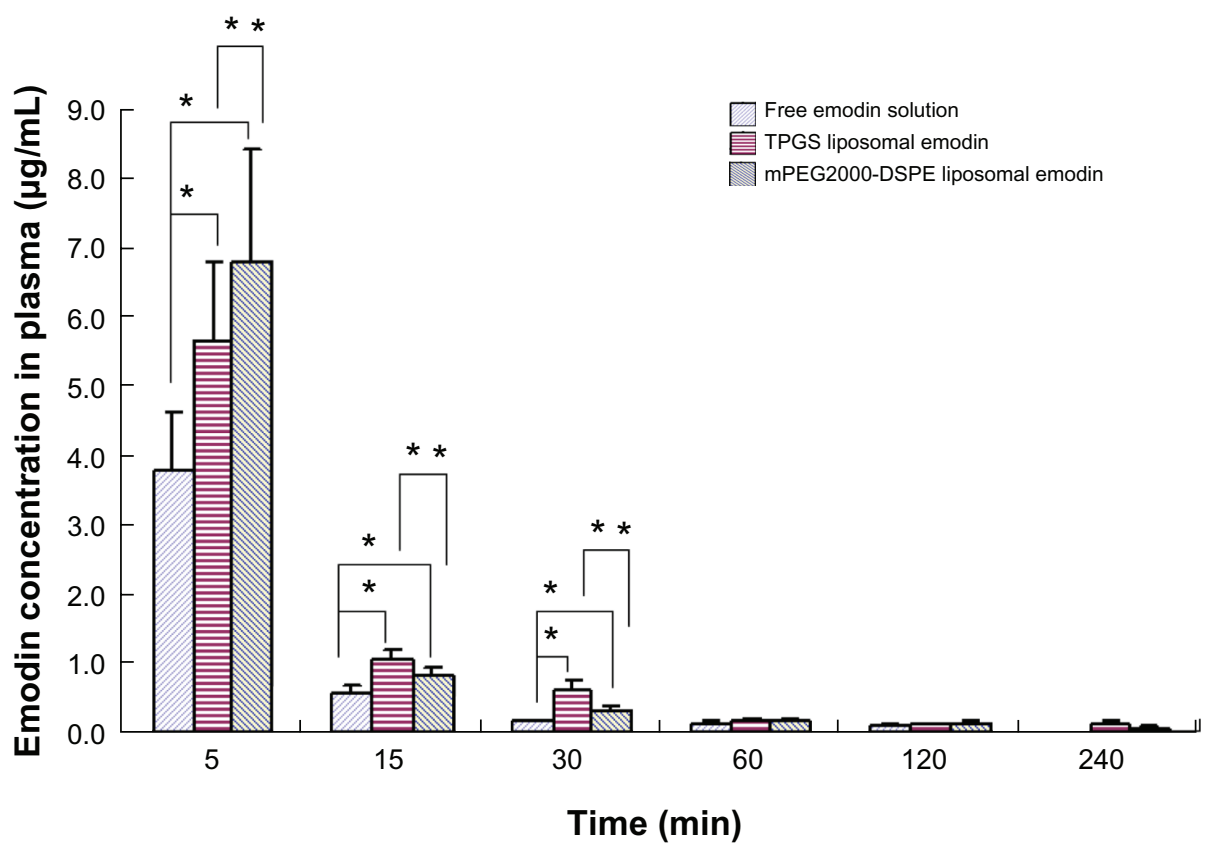

Figure 6 Plasma concentration-time profile $(n=5)$.

Notes: *Refers to significant difference in comparison with free emodin solution $(P<0.04)$; **refers to significant difference in comparison with TPGS liposomal emodin $(P<0.04)$.

Abbreviations: TPGS, D- $\alpha$-tocopheryl polyethylene glycol 1000 succinate; mPEG2000-DSPE, methoxypolyethyleneglycol 2000-derivatized distearoyl-phosphatidylethanolamine.

concentrations of emodin in plasma quickly decreased. During the first 30 minutes postadministration of various formulations, both TPGS- and mPEG2000-DSPE-modified liposomes significantly improved the plasma concentrations of emodin and relatively prolonged the circulation time of emodin in comparison with free emodin. It is interesting that at 5 minutes postadministration, the plasma concentration of mPEG2000-DSPE liposomes was significantly higher than that of TPGS liposomes, while at 15 minutes and 30 minutes, the opposite results were obtained. The area under the concentration-time curve (AUC) calculated using Phoenix WinNonlin 5.2 (Pharsight, St Louis, MO) showed that both TPGS and mPEG2000-DSPE liposomes promoted the retention of emodin in plasma, with AUC 1.7 times and 1.9 times that of free emodin solution, respectively.

Biodistributions of various emodin formulations in the main organs such as the heart, liver, spleen, lung, and kidney are shown in Figure 7. It is noteworthy that both liposomes containing TPGS and mPEG2000-DSPE significantly elevated the emodin concentration in the heart in comparison with free emodin. Except at 15 minutes, significant differences for TPGS liposomal emodin and mPEG2000-DSPE liposomal emodin were observed (Figure 7A). Compared to free emodin, a 3.0-fold AUC for TPGS liposomal emodin and a 2.3-fold AUC for mPEG2000-DSPE liposomal emodin were also obtained (Table 5). It has been reported that emodin showed a specific effect for artery restenosis, ${ }^{8,9}$ and the nanoparticles could work as the carrier for restenosis. ${ }^{25}$ Accumulation of emodin liposomes in the heart suggests that liposomes conjugating TPGS or mPEG2000-DSPE could be a potential carrier for emodin targeting against restenosis.

Data in Figure 7B showed that at 5 minutes postadministration of the various formulations, the mPEG2000-DSPE liposomes took much more emodin into the liver compared to TPGS liposomes or free emodin. However, the emodin concentrations decreased quickly. At 15 minutes, there was no significant difference between the TPGS liposomes and mPEG2000-DSPE liposomes, while at 30 minutes, the emodin concentration of TPGS liposomes was significantly higher than that of the mPEG2000-DSPE liposomes. Later, no significant differences were observed among the three formulations. These data showed that emodin liposomes quickly distributed into the liver after the intravenous injection.

There were no significant differences between TPGS liposomal emodin and mPEG2000-DSPE liposomal emodin in the spleen (Figure 7C). It is surprising that free emodin showed similar concentration versus time profiles and AUCs to TPGS liposomal emodin and mPEG2000-DSPE liposomal emodin in the liver and spleen. Emodin is a poorly water-soluble drug, which is dispersed in saline and further dissolved by adding $\mathrm{NaOH}$ solution to achieve a $\mathrm{pH}$ value of 10.0 for injection. Thus, we speculate that parts of the 

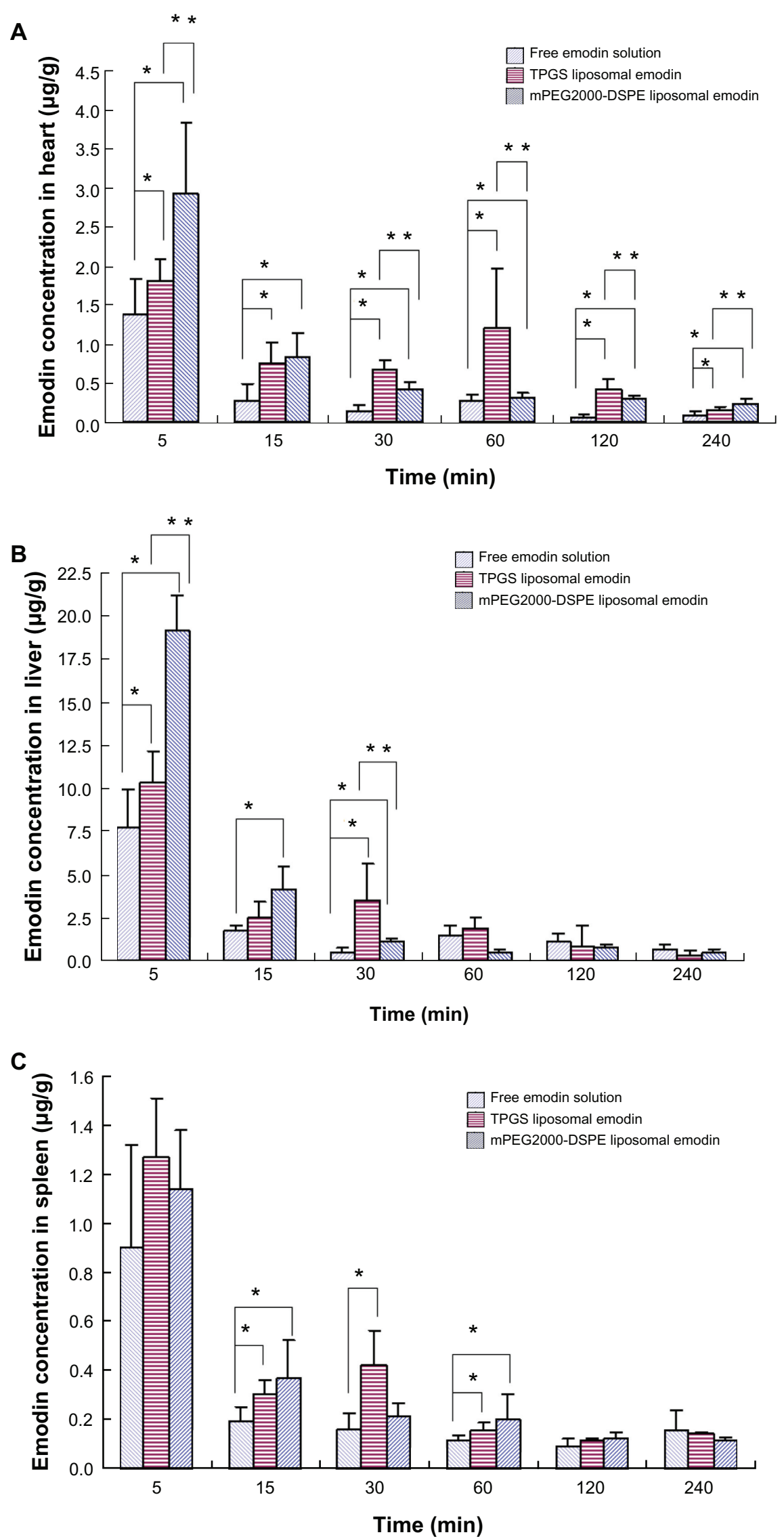

Figure 7 (Continued) 

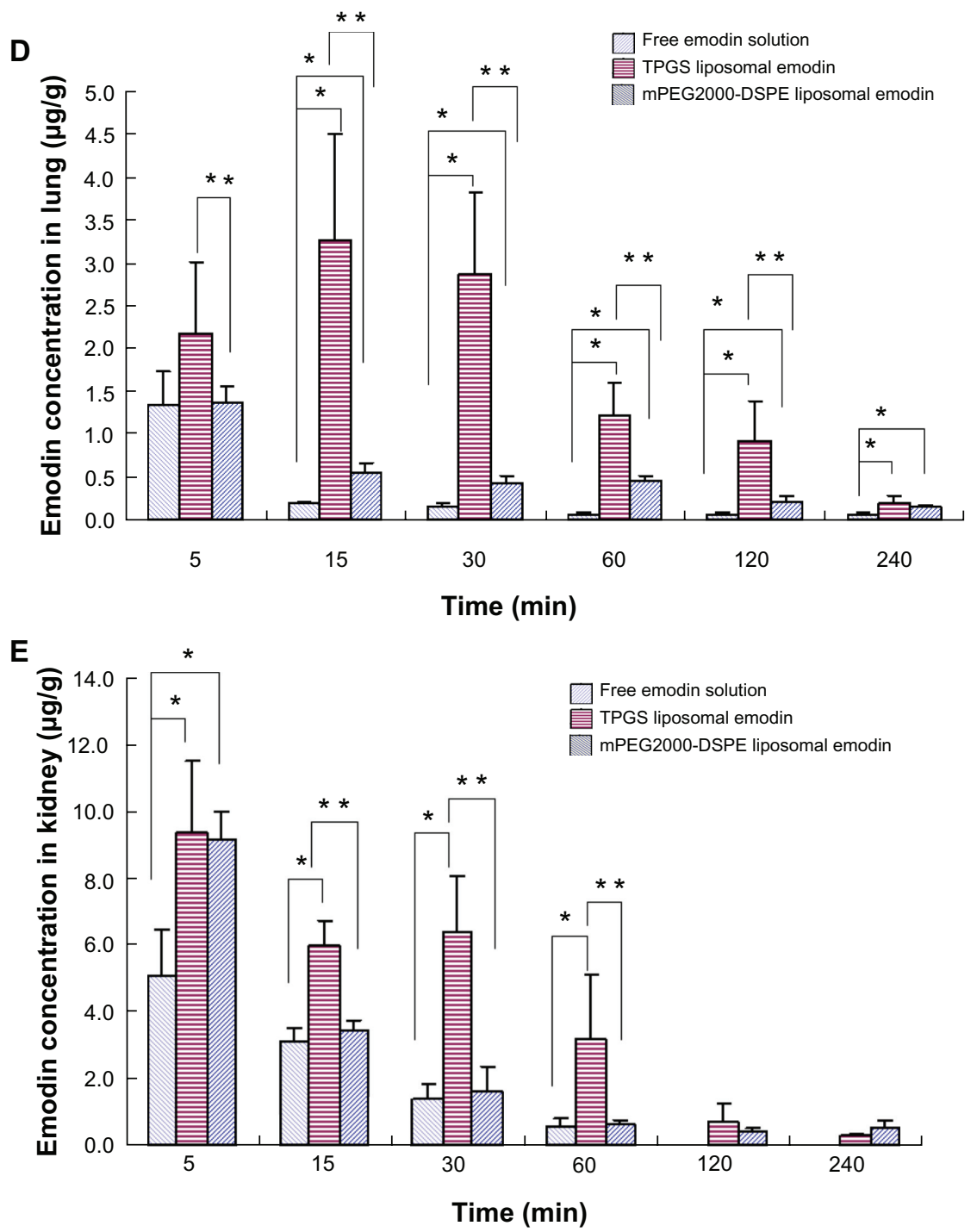

Figure 7 Biodistribution of emodin in the (A) heart, (B) liver, (C) spleen, (D) lung and (E) kidney $(n=5)$.

Notes: *Refers to significant difference in comparison with free emodin solution $(P<0.04)$; **refers to significant difference in comparison with TPGS liposomal emodin $(P<0.04)$.

Abbreviations: TPGS, D- $\alpha$-tocopheryl polyethylene glycol 1000 succinate; mPEG2000-DSPE, methoxypolyethyleneglycol 2000-derivatized distearoyl-phosphatidylethanolamine.

dissolved emodin in the alkaline solution may precipitate as drug nanocrystals after bolus injection into the blood vessels, and the nanocrystals are then taken into the liver and spleen by MPS phagocytosis. In addition, liposomes significantly enhanced emodin retention in the lung and kidney compared to free emodin (Figure 7D and E). TPGS liposomes also showed three times and two times greater AUCs than mPEG2000DSPE in the lung and kidney, respectively (Table 5). Emodin is a multifunctional drug extracted from the Chinese herbs. Antifibrosis in the liver, ${ }^{6,7}$ lungs $^{5}$ and kidneys ${ }^{26}$ have been extensively studied. From the above biodistribution studies, the data suggest that TPGS liposomes could be a potential

Table 5 AUC values of emodin in various formulations $(\mu \mathrm{g} \cdot \mathrm{min} / \mathrm{mL}, \mu \mathrm{g} \cdot \mathrm{min} / \mathrm{g})$

\begin{tabular}{|c|c|c|c|c|c|c|}
\hline Formulations & Plasma & Heart & Liver & Spleen & Lung & Kidney \\
\hline Free emodin & 69.79 & 48.04 & 332.90 & 40.65 & 37.30 & 132.68 \\
\hline TPGS liposomal emodin & 122.02 & 145.85 & 411.42 & 55.10 & 275.53 & 540.30 \\
\hline mPEG2000-DSPE liposomal emodin & 133.74 & 109.40 & 435.85 & 50.16 & 81.06 & 278.20 \\
\hline
\end{tabular}

Abbreviations: AUC, area under the emodin concentration versus time curve; $\mu \mathrm{g}$, microgram; min, minute; mL, milliliter; g, gram; TPGS, $\mathrm{D}$ - $\alpha$-tocopheryl polyethylene glycol 1000 succinate; mPEG2000-DSPE, methoxypolyethyleneglycol 2000-derivatized distearoyl-phosphatidylethanolamine. 
delivery carrier of emodin for treating leukemia, artery restenosis, and fibrosis in the liver, lungs, and kidneys.

\section{Conclusion}

In this study, a novel liposomal vesicle containing TPGS was formulated to entrap emodin, which showed a desirable EE, particle size, ultrastructural morphology, physical stability, in vitro release profile, and in vivo pharmacokinetics and biodistrubution in comparison with mPEG2000-DSPE liposomal emodin. In addition, TPGS liposomes enhanced the cytotoxicity of emodin to L1210, K562, and MV4-11 leukemia cells more than mPEG2000-DSPE liposomal emodin, and Tf further promoted the antileukemia effect by regulation of Bcl-2 family membranes, such as Mcl-1, Bcl-2, and Bax. In conclusion, TPGS is a potential pegylated agent to compose liposomes for emodin.

\section{Acknowledgments}

This work was funded by the Chinese Traditional Medicine Bureau of Zhejiang Province grant 2005C045.

\section{Disclosure}

The authors report no conflicts of interest in this work.

\section{References}

1. Muto A, Hori M, Sasaki Y, et al. Emodin has a cytotoxic activity against human multiple myeloma as a Janus-activated kinase 2 inhibitor. Mol Cancer Ther. 2007;6(3):987-994.

2. Yeh FT, Wu CH, Lee HZ. Signaling pathway for aloe-emodin-induced apoptosis in human H460 lung nonsmall carcinoma cell. Int J Cancer. 2003;106(1):26-33.

3. Yu CX, Zhang XQ, Kang LD, et al. Emodin induces apoptosis in human prostate cancer cell LNCaP. Asian J Androl. 2008;10(4):625-634.

4. Hsu CM, Hsu YA, Tsai Y, et al. Emodin inhibits the growth of hepatoma cells: finding the common anticancer pathway using Huh7, Hep3B, and HepG2 cells. Biochem Biophys Res Commun. 2010;392(4):473-478.

5. Chen XH, Sun RS, Hu JM, et al. Inhibitory effect of emodin on bleomycin-induced pulmonary fibrosis in mice. Clin Exp Pharmacol Physiol. 2009;36(2):146-153.

6. Dong MX, Jia Y, Zhang YB, et al. Emodin protects rat liver from CCl(4)induced fibrogenesis via inhibition of hepatic stellate cells activation. World J Gastroenterol. 2009;15(38):4753-4762.

7. Gui M, Zhang YF, Xiao ZY, et al. Inhibitory effect of emodin on tissue inhibitor of metalloproteinases-1 (TIMP-1) expression in rat hepatic stellate cells. Dig Dis Sci. 2007;52(1):200-207.

8. Heo SK, Yun HJ, Park WH, Park SD. Emodin inhibits TNF-alpha-induced human aortic smooth-muscle cell proliferation via caspase- and mitochondrial-dependent apoptosis. J Cell Biochem. 2008;105(1):70-80.
9. Wang X, Zou Y, Sun A, et al. Emodin induces growth arrest and death of human vascular smooth muscle cells through reactive oxygen species and p53. J Cardiovasc Pharmacol. 2007;49(5):253-260.

10. Alves DS, Perez-Fons L, Estepa A, Micol V. Membrane-related effects underlying the biological activity of the anthraquinones emodin and barbaloin. Biochem Pharmacol. 2004;68(3):549-561.

11. Gobin AS, Rhea R, Newman RA, Mathur AB. Silk-fibroin-coated liposomes for long-term and targeted drug delivery. Int J Nanomedicine. 2006;1(1):81-87.

12. Cheema SK, Gobin A, Rhea R, Lopez-Berestein G, Newman RA, Mathur AB. Silk fibroin mediated delivery of liposomal emodin to breast cancer cells. Int J Pharm. 2007;341(1-2):221-229.

13. Lotem M, Hubert A, Lyass O, et al. Skin toxic effects of polyethylene glycol-coated liposomal doxorubicin. Arch Dermatol. 2000;136(12):1475-1480.

14. Shah AR, Banerjee R. Effect of d- $\alpha$-tocopheryl polyethylene glycol 1000 succinate (TPGS) on surfactant monolayers. Colloids Surf B Biointerfaces. 2011;85(2):116-124.

15. Mu L, Elbayoumi TA, Torchilin VP. Mixed micelles made of poly(ethylene glycol)-phosphatidylethanolamine conjugate and d-alphatocopheryl polyethylene glycol 1000 succinate as pharmaceutical nanocarriers for camptothecin. Int J Pharm. 2005;306(1-2):142-149.

16. Dilnawaz F, Singh A, Sahoo SK. Transferrin-conjugated curcuminloaded superparamagnetic iron oxide nanoparticles induce augmented cellular uptake and apoptosis in K562 cells. Acta Biomater. 2012;8(2):704-719.

17. Yang X, Koh CG, Liu S, et al. Transferrin receptor-targeted lipid nanoparticles for delivery of an antisense oligodeoxyribonucleotide against Bcl-2. Mol Pharm. 2009;6(1):221-230.

18. Macedo MF, de Sousa M. Transferrin and the transferrin receptor: of magic bullets and other concerns. Inflamm Allergy Drug Targets. 2008;7(1):41-52.

19. Yu B, Tai HC, Xue W, Lee LJ, Lee RJ. Receptor-targeted nanocarriers for therapeutic delivery to cancer. Mol Membr Biol. 2010;27(7): 286-298.

20. Liang JW, Hsiu SL, Wu PP, Chao PDL. Emodin pharmacokinetics in rabbits. Planta Med. 1995;61(5):406-408.

21. Chun-Guang W, Jun-Qing Y, Bei-Zhong L, et al. Antitumor activity of emodin against human chronic myelocytic leukemia K562 cell lines in vitro and in vivo. Eur J Pharmacol. 2010;627(1-3):33-41.

22. Lee HZ, Hsu SL, Liu MC, Wu CH. Effects and mechanisms of aloeemodin on cell death in human lung squamous cell carcinoma. Eur $J$ Pharmacol. 2001;431(3):287-295.

23. Pecere T, Sarinella F, Salata C, et al. Involvement of p53 in specific antineuroectodermal tumor activity of aloe-emodin. Int $J$ Cancer. 2003;106(6):836-847.

24. Chen YC, Shen SC, Lee WR, et al. Emodin induces apoptosis in human promyeloleukemic HL-60 cells accompanied by activation of caspase 3 cascade but independent of reactive oxygen species production. Biochem Pharmacol. 2002;64(12):1713-1724.

25. Brito L, Amiji M. Nanoparticulate carriers for the treatment of coronary restenosis. Int J Nanomedicine. 2007;2(2):143-161.

26. Li X, Liu W, Wang Q, et al. Emodin suppresses cell proliferation and fibronectin expression via p38MAPK pathway in rat mesangial cells cultured under high glucose. Mol Cell Endocrinol. 2009;307(1-2): $157-162$.
International Journal of Nanomedicine

\section{Publish your work in this journal}

The International Journal of Nanomedicine is an international, peerreviewed journal focusing on the application of nanotechnology in diagnostics, therapeutics, and drug delivery systems throughout the biomedical field. This journal is indexed on PubMed Central, MedLine, CAS, SciSearch $₫$, Current Contents ${ }^{\circledR} /$ Clinical Medicine,

\section{Dovepress}

Journal Citation Reports/Science Edition, EMBase, Scopus and the Elsevier Bibliographic databases. The manuscript management system is completely online and includes a very quick and fair peer-review system, which is all easy to use. Visit http://www.dovepress.com/ testimonials.php to read real quotes from published authors. 